УДК 808.1

\title{
А.Э. Якубовский
}

\section{ПРИЗРАК АВТОРА. ПОЭТИЧЕСКИЙ ЯЗЫК, ПЕРЕВОД И ФАНТОМИЗАЦИЯ АВТОРСТВА}

Противопоставляются национальный язык и язык художественной литературы как непрерывное и дискретное образования. Предлагается модель художественного перевода как фантомизации - формирования образа фиктивного автора (призрак или фантом автора), способного оказывать влияние на литературный процесс аналогично реально существовавшему автору (вторичная фантомизация). Обсуждается роль перевода в развитии современных национальных литератур народов Российской Федерации.

Ключевые слова: автор, художественный перевод, фантомизация, узус, национальные языки.

DOI: $10.35634 / 2412-9534-2021-31-2-342-346$

Проблема поэтического перевода достаточно полно исследована и представляет собой отдельный и очень объемный пласт теории литературы. Однако существуют моменты, которые очевидно не могут быть решены хорошо отработанными филологическими методами и требуют более отстраненного взгляда на проблему.

Общепризнано, что в отличие от коммуникативного (достаточного для понимания содержания), перевод художественный (и, в частности, поэтический) - не просто проекция совокупности смыслов одной лексической системы (языка) в другую. Технически можно считать перевод художественного текста отображением некоего подмножества языка оригинала, именуемого «языком автора», в подмножество языка перевода, причем это второе подмножество исходно не существует и создается именно процессом перевода. Почему так происходит?

В отличие от языка в широком смысле, который един и непрерывен, язык художественных (литературных) произведений (чтобы не путать с «литературным языком» как уровнем, высшей формой общенародного/национального языка, условно будем именовать его «поэтическим языком») дискретен. Пространство поэтического языка состоит из отдельных текстов, объединенных создавшими их авторами, которые в свою очередь, могут группироваться в отдельные школы или течения. Эти тексты можно сравнить с островами, находящимися в океане узуса, но возвышающимися над ним. Если уточнить образ, то язык отдельного поэта является скорее айсбергом, нежели островом, поскольку с течением времени может раствориться, пополнив океан обыденной речи. Роль литературы в обогащении лексики общеизвестна; при этом не столь важно, придумано ли, например, слово «летчик» непосредственно Грином или Хлебниковым, или же они лишь услышали его, оценили и ввели во всеобщий оборот. Появление новых слов в поэтическом языке и затем переход их в узус - нормальное явление.

Возможно ли вообще литературное (художественное) творчество, поэтический язык на уровне узуса? Версификация однозначно возможна: в любом коллективе найдется талант, сочиняющий поздравления на Новый год или юбилей Петра Ивановича вполне сносным пятистопным ямбом. Однако Аристотель, «Поэтика» которого не только источник всего европейского литературоведения, но и до сих пор - чистый родник мысли, однозначно полагал, что поэтическая (художественная) речь должна осмысленно («в меру») использовать редкую, не являющуюся общеупотребительной лексику: «возвышенный и свободный от грубоватости слог пользуется чуждыми обыденной речи словами. Чуждыми я называю глоссу, метафору, растяжение и все, что выходит за пределы обыденного говора... Глоссы, метафоры, украшения и другие виды слов, упомянутые мною, сделают слог благородным и возвышенным, а общеупотребительные выражения придадут ему ясность» [1]. При этом в качестве критерия поэтического таланта Аристотель выделяет именно метафору, то есть противоположное узуальному словоупотребление.

Конечно, лингвистический уровень не покрывает понятие «поэтического языка», ибо под ним следует понимать совокупность всех выразительных средств произведения, даже если мы условно называем его «текст»: помимо чисто языковых там есть ритмические и визуальные моменты (метр, рифма, строфика, шрифтовое оформление - например, выделение курсивом или игнорирование прописных, не говоря уже о каллиграммах), специфика образности автора, и, разумеется, жанровые особенности, определяющие круг тем и сюжетов. За ними (или, точнее, над ними, если считать чисто 
речевые средства «уровнем моря») лежат эстетические представления, включающие самоосознание автора, предназначение и роль творчества и т. д.

Каждый этот «остров» принадлежит какому-то автору, поэтому здесь термины «автор» и «совокупность текстов одного автора» употребляются как синонимы; вполне допустимо объединять эти острова в архипелаги и континенты по эпохам, литературным школам, и т.д. Важно лишь, что пространство художественного (поэтического) языка дискретно, и отдельные его участки индивидуальны; мы достаточно часто способны по краткой цитате опознать (идентифицировать) автора. Овладение поэтическим языком - и читателя, и начинающего автора - происходит также дискретно; язык художественных произведений усваивается по мере перехода от одного текста (естественно, имеющего конкретного автора) к другому. Известны случаи, когда литератор задерживается на определенном «острове» (или «архипелаге» направления, литературной школы) и создает собственное произведение с использованием чужого художественного языка; в этом случае литературоведы говорят о влиянии, подражании, пастише или даже о ложном авторстве. Некоторые авторы, не желая отойти от разработки уже созданных другими богатств, навсегда остаются «на чужом берегу» (в этом случае их считают эпигонами), некоторые преодолевают эту зависимость и идут дальше в океан родного языка.

Разумеется, вышеприведенная схема - в том числе из-за навязчивой метафоричности - может показаться достаточно тривиальной. Однако у нее есть интересные следствия, на два из которых я предлагаю обратить внимание.

Поскольку корпус переводных текстов с присущим ему языком (в широком смысле слова) является подмножеством не только иной литературной традиции, но и иного национального языка, то перевод (или совокупность переводов) создает некую фиктивную реальность в рамках языка перевода, - то, что филологи называют именем поэта с добавлением прилагательного «русский»: «русский Шекспир», «русский Верлен» и т. д. В случае удачных (т. е. сильных, имеющих безусловную художественную ценность, ибо не все переводы таковы), возникает иллюзия, призрак еще одного русскоязычного поэта (в реальности никогда не существовавшего, однако живого - в том же смысле, как являются живыми языки, на которых продолжают возникать новые тексты) ${ }^{1}$, обогащающего своим творчеством корпус русской поэзии и влияющего на поэтические практики реально существующих русскоязычных авторов. Не было никакого реального Шекспира, пишущего по-русски, и в то же время как автор он зримо существует, пусть как некий призрак; поэтому воспользуемся выражением «фантомизация авторства».

Формально «русский Шекспир» - совокупность текстов, созданных за двести с лишнем лет несколькими десятками реально существовавших людей. Но можно ли считать, что «русский Шекспир» как автор, как личность поэта, с которым можно вести диалог, спорить, которому можно подражать и у которого можно учиться - это условное название коллектива переводчиков? Широко известна максима про конгениальность переводчика автору; но искомая конгениальность не есть тождество. И не только в том значении, в котором автор эпиграммы утверждал, что «Маршак остался Маршаком, а Роберт Бернс - поэтом»; прежде всего примем во внимание, что основа перевода (сюжет, образность, метрика и т.д.) берется из чужого поэтического языка, и, переводя, автор перевода - вполне по Станиславскому - «живет в образе» иноязычного автора, добиваясь на момент творчества временного уподобления, самоотождествления с автором оригинала. Тот же Маршак, кстати, говорил, что «стихи не переводят, их проживают». Когда мы произносим «Шекспир жив» - это не метафора, ибо с каждым новым переводом, с каждой новой театральной постановкой, с каждой новой аллюзией на его тексты в стихах современных поэтов он актуализируется и всегда остается нашим современником. В этом, как хорошо известно литературоведам, и состоит отличие «классического произведения» от «литературного памятника».

Взаимоотношения между автором и переводчиком, разумеется, могут быть разными - от полного растворения автора в переводчике до, напротив, элиминации переводчика автором; отметим лишь крайние точки спектра.

\footnotetext{
${ }^{1}$ «Множественность параллельных переводов» выделяется исследователями как одна из основных особенностей переводной литературы» (Е. А. Первушина). Однако положение о том, что «в пространстве межкультурных коммуникаций переводная литература должна занять какую-то другую, особенную, наднациональную нишу» [6, с. 178] кажется избыточным; собственно, данная статья предлагает альтернативное объяснение уникальности переводной литературы через механизм фантомизации.
} 
Трудно переоценить роль Жуковского в развитии русского поэтического языка. Хотя собственно оригинальных произведений у него немного, однако тот корпус западноевропейского романтизма и эпической поэзии, которые он ввел в русскую литературу, оказал огромное влияние на последующее развитие поэзии; «у меня почти все или чужое, или по поводу чужого - и все, однако, мое» - писал сам Василий Андреевич в письме Гоголю от 6 (18) февраля 1848 года [3]. Поэтому по переводу Жуковского трудно отличить Уланда от Гебеля - фактически он переводил их произведения как некий единый романтический текст или, скорее, некую хрестоматию того, что следовало знать о немецком романтизме русскому читателю. Если привлекать лингвистические аналогии, то мы имеем дело с его личностным «изводом» романтизма. Более того, вполне допустимо предположить, что для Жуковского все переводимые им тексты были лишь проявлением единого духа поэзии, говорящего разными устами (для романтиков, если не делить их по советской привычке на «религиозных» и «революционных», представление о вдохновленности свыше было общим местом), некоего Поэта (с заглавной буквы) как такового, в котором растворяется личность автора/переводчика. Точно так же, рассматривая переводы Маршака с разных языков, объединяемые под названием «детские стихи и песенки», мы вряд ли отличим английский источник от чешского или латышского, не заглядывая в комментарий - но здесь уже исходные тексты без остатка растворяются в личности переводчика. Отчасти потому, что Маршак стоял у самого истока жанра в русскоязычной литературе и создал образец для дальнейшего его развития, есть подозрения, что некоторые позднесоветские авторы выдавали за «переводы с английского» оригинальные стилизации, вдохновленные именно версификационным гением Маршака. Таким образом, это противоположный полюс взаимоотношений автора и переводчика.

Существуют примеры, когда индивидуальная стилистика иноязычного автора в русском переводе оказывается настолько удачной, что не только создает вполне осязаемый образ, но и вызывает огромное число подражаний на грани пастиша или даже ложного авторства. Каждый сталкивался с рубаи, которых никогда не писал Омар Хайям и, соответственно, никогда не переводили ни Константин Бальмонт, ни Владимир Державин, ни Герман Плисецкий. Однако «русский Хайям» жив, и мы ежедневно знакомимся с его новыми стихами в социальных сетях. В данном случае группа талантливых переводчиков на протяжении века создала такой яркий сгусток поэтической индивидуальности, что он вызывает вторичную поэтическую фантомизацию - подражание подражанию.

Нельзя сказать, что это возможно только в случае перевода - вторичная фантомизация возможна и в пределах одного национального языка, хотя встречается значительно реже (поскольку и собственно фантомизация в пределах одной культурно-языковой традиции является избыточной). Так, близким аналогом Омара Хайяма служит Козьма Прутков, являющийся образцом для стилистического подражания позднейших сатириков.

Таким образом, талантливая переводческая работа способна создать фантом - призрак автора, воспринятый читателем как самостоятельный феномен отечественной литературы, точно так же функционирующий в ее составе, как и реально существовавшие авторы. Вторичная фантомизация, т.е. подражание реальных авторов этому фантому, - существенное явление в развитии литературы и, в частности, поэтического языка. Сколько российских литераторов прошлого века были очарованы Киплингом или Хемингуэем, и если не подражали прямо, то испытывали их влияние в какой-то (обычно ранний) период творчества, пока не выработали собственной, оригинальной стилистики? примеров достаточно.

Поэтому поэтический язык прирастает не только отечественными авторами, но и переводными. Даже если период формирования национальной литературы, когда переводные произведения составляют подавляющее большинство, остается далеко в прошлом («А разве есть русские романы?»спрашивала графиня в «Пиковой даме» Пушкина), то такой взаимообмен остается чрезвычайно важным средством расширить поле национального художественного языка (увеличить корпус текстов не только количественно, но и повысить его качественное разнообразие за счет авторов-фантомов) и тем самым способствовать развитию языка как такового.

Отсюда второе следствие из вышеприведенной схемы, на первый взгляд противоречащее здравому смыслу. В настоящее время вектор усилий как самих писателей, так и ответственных за данный сегмент духовной жизни государственных структур направлен вовне, на развитие перевода как средства расширения доступности текстов национальных авторов: с языков «малых народов» Российской Федерации на русский, с русского - на зарубежные языки. Хороший обзор ситуации с анализом причин дает А.П. Расторгуев [7], и трудно не согласиться с его аргументами; однако стоит взглянуть на проблему и с точки зрения поэтического (художественного) языка. Официальной задачей региональ- 
ных министерств культуры и аналогичных органов по делам национальностей считается сохранение родного языка - именно сохранение, а не развитие («сохранение глубинных, базовых основ многонациональной культуры России, национальных языков и литературы, значимых традиций, памятников фольклора, защита культурной самобытности каждого народа России» [5]). Безусловно, это совершенно верная постановка вопроса (страшно представить, что произойдет, если мы на государственном уровне поручим чиновникам реформировать живые языки). Следует заметить, что проблема «сохранение самобытности vs развитие через заимствования», как верно отмечает Н.К. Гарбовский, всегда возникает в переломные моменты развития национального языка; и официальная установка государства в интерпретации учреждений культуры национальных республик и автономий не слишком отличается от позиции Гердера, сравнивавшего «национальный язык, до того, как на него начинают переводить, с юной девственницей. Речь на таком языке чиста и непорочна, она же есть точное отражение характера своего народа. Даже будучи бедной, капризной и непоследовательной, она отражает исконно национальную культуру. Девственница не задумывается над тем, какой плод может появиться на свет в результате смешения кровей» [2]. Однако любой язык нуждается не только в сохранении (консервации), но и в развитии, которое - как уже сказано выше - идет в том числе и через развитие национального художественного языка, поскольку взаимообмен узуса и языка художественных текстов - самый естественный способ приращения для обеих сторон.

Для этого же необходим обратный вектор: переводы с иностранных языков на национальный. К сожалению, вопрос о переводах Овидия на коми или Сен-Жон Перса на башкирский сплошь и рядом вызывает лишь искреннее удивление. «Кому захочется, прочитает на русском, а кто по-русски не умеет, тот этими авторами вряд ли заинтересуется», - отвечали мне в личных беседах даже поэты, сами работающие в области перевода. В несколько меньшей степени это касается и перевода современных русскоязычных поэтов на языки тех республик, в которых они живут и работают. Другой же стороной проблемы являются жалобы на скудность и неразвитость национальных языков, затрудняющих перевод и создание оригинальных художественных произведений на них, из-за чего многие двуязычные в быту авторы выбирают языком своего творчества русский.

Следует оговориться: речь в данном случае идет о поэтических языках. На уровне бытового общения - условно приравненном в данном случае к узуальному уровню - все живые языки, пользуясь математическим термином, «равномощны», раз уж они обеспечивают полноценное общение в семье, в быту, в социальных сетях. Но, не развиваясь на уровне литературного языка, они обречены на отставание и некритическое заимствование иноязычной лексики и языковых моделей. Вспомните русский язык XVIII в. - он тоже был достаточно «неразвит» и «необустроен»; однако усилиями российских литераторов буквально за полвека прошел огромный путь от Кантемира до Пушкина. Благодаря, повторюсь, в том числе и титаническому подвигу российских переводчиков.

Возможно, следует вернуться к опыту коллективных переводов 1920-х гг., когда для русского читателя открылись совершенно новые литературные горизонты - например, академик Н.И. Конрад с учениками впервые систематически перевел (пусть в ограниченном объеме) и прокомментировал основные произведения японской литературы, создав полноценную хрестоматию, не имевшую в то время аналогов на европейских языках [4]. Переводы мировой классики вкупе с комментариями и разбором техники - вполне адекватная учебная работа для старшекурсников национальных университетов (кстати, это давно принято в китайских языковых вузах). Речь идет не только о количественном расширении корпуса текстов на национальном языке, но и об эксперименте по освоению художественных форм и способов выражения, созданных мировой литературой. Объединив усилия национальных поэтов, лингвистов, литературоведов и поддержав их достаточно скромными грантами на издание полученных результатов, мы могли бы через некоторое время получить более высокий базовый уровень для развития национальных литератур народов нашей общей страны.

\section{СПИСОК ЛИТЕРАТУРЫ}

1. Аристотель. Поэтика. URL: http://nevmenandr.net/poetica/1458a18.php (цитируется перевод Н. Новосадского).

2. Гарбовский H.K. Лекция 12. Переводной дискурс. Перевод и словесность принимающей культуры. URL: https://link.ac/5FH729

3. Жуковский В.А. Письмо к Н.В. Гоголю от 6 (18) февраля 1848 года // Жуковский В.А. Собр. соч. Т. 4. М.; Л., 1960. C. 544. URL: https://rvb.ru/19vek/zhukovsky/01text/vol4/03letters/380.htm

4. Конрад Н.И. Японская литература в образцах и очерках / АН СССР, Ин-т востоковедения. репринтное изд. М.: Наука, 1991. 551, [1] с. 
5. Концепция сохранения и развития нематериального культурного наследия народов Российской Федерации на 2009-2015 годы. URL: http://docs.cntd.ru/document/902160920

6. Первушина Е.А. Художественный перевод как проблема сравнительного литературоведения // Rosa Mundi. К 90-летию преподавания истории зарубежных литератур в ДВГУ. Владивосток: Изд-во Дальневост. ун-та, 2007. C. 174-181.

7. Расторгуев А.П. «Мы снова говорим на разных языках...». О проблемах художественного перевода в современной отечественной литературе. К докладу на XX конференции Ассоциации писателей Урала, Поволжья и Сибири (Сыктывкар, 6 ноября 2019 г.). URL: https://aspur.ru/a-rastorguev-o-problemah-hudozhestvennogo-perevoda/

Поступила в редакцию 13.08.2020

Якубовский Андрей Эдуардович, младший научный сотрудник отдела философии

Институт философии и права Уральского отделения РАН

620990, Россия, г. Екатеринбург, ул. Софьи Ковалевской, 16

E-mail: ayac@yandex.ru

ORCID 0000-0002-6379-8182

\section{A.E. Yakubovsky \\ PHANTOM OF THE AUTHOR. \\ POETIC LANGUAGE, TRANSLATION AND PHANTOMIZATION OF THE AUTHORSHIP}

DOI: $10.35634 / 2412-9534-2021-31-2-342-346$

National language and language of fiction are contraposed as continuous and discrete entities. We propose a model of literary translation as a phantomization of the author: a creation of an image of a fictitious author (a phantom author), which is capable of influencing the literary process as a real author (the secondary phantomization). The role of translation is discussed in the context of development of modern national literatures of the Russian Federation.

Keywords: author, literary translation, phantomization, usus, national languages.

\section{REFERENCES}

1. Aristotle. De Poetica. Ch. 22, 1458a. Available at: http://nevmenandr.net/poetica/1458a18.php (in Russian).

2. Garbovskij N. K. Lekcija 12. Perevodnoj diskurs. Perevod i slovesnost' prinimajushhej kul'tury [Lecture 12. Translated discourse. Translation and literature of the host culture] (in Russian). Available at: https://link.ac/5FH729

3. Zhukovsky V. Pis'mo k N.V. Gogolyu ot 6 (18) fevralya 1848 goda [Letter to N. Gogol 6(18) feb. 1848]. V.A. Zhukovsky, Collected Works, V. 4. Moscow, Leningrad, 1960, p. 544 (in Russian). Available at: https://rvb.ru/ 19vek/zhukovsky/01 text/vol4/03letters/380.htm

4. Konrad N. Yaponskaya literatura v obraztsakh i ocherkakh [Japanese Literature in Samples and Essays]. Moscow, Nauka, 1991 (reprint of edition Leningrad, 1927). (in Russian).

5. Koncepcija sohranenija i razvitija nematerial'nogo kul'turnogo nasledija narodov Rossijskoj Federacii na 2009-2015 gody [The concept of preservation and development of the intangible cultural heritage of the peoples of the Russian Federation for 2009-2015] (in Russian). Available at: http://docs.cntd.ru/document/902160920

6. Pervushina E. A. Hudozhestvennyj perevod kak problema sravnitel'nogo literaturovedenija [Literary translation as a problem in comparative literary studies] Rosa Mundi. K 90-letiju prepodavanija istorii zarubezhnyh literatur $\mathrm{v}$ DVGU. Vladivostok: Izd-vo Dal'nevost. un-ta, 2007. Pp. 174-181 (in Russian).

7. Rastorguev A.P. «My snova govorim na raznykh yazykakh...». O problemakh khudozhestvennogo perevoda v sovremennoy otechestvennoy literature. K dokladu na XX konferentsii Assotsiatsii pisateley Urala, Povolzh'ya i Sibiri (Syktyvkar, 6 noyabrya 2019 g.) ["We are again talking in different languages...". On the problems of literary translation in modern Russian literature. For the report at the XX conference of the Association of Writers of the Urals, Volga region and Siberia (Syktyvkar, November 6, 2019)]. (in Russian) Available at: https://aspur.ru/arastorguev-o-problemah-hudozhestvennogo-perevoda/

Yakubovskiy A.E., Junior Researcher

Institute of Philosophy and Law, Ural Branch of the Russian Academy of Sciences

Sofii Kovalevskoy st., 16, Yekaterinburg, Russia, 620990

E-mail: ayac@yandex.ru 